\title{
Psychometric evaluation of the Sinhalese version of MacNew Heart Disease Health Related Quality of Life Questionnaire in patients with stable angina
}

K. L. M. D. Seneviwickrama* ${ }^{*}$, D. B. D. L. Samaranayake², P. Fonseka ${ }^{3}$, G. N. L. Galappaththy ${ }^{4}$, S. Höfer ${ }^{5}$ and N. B. Oldridge ${ }^{6}$

\begin{abstract}
Background: A Sinhalese version of a validated, disease-specific patient-reported heart disease health related quality of life instrument is lacking. The purpose of this study was to validate the interviewer-administered Sinhalese version of the MacNew Heart Disease Health-related Quality of Life Questionnaire (MacNew) in patients with clinically diagnosed stable angina.

Methods: The Sinhalese translation of the MacNew was carried using standard forward- backward translation technique. In this validation study, the MacNew was administered to 200 patients with stable angina. Reliability was assessed by internal consistency and test-retest reliability. Construct validity was explored by exploratory factor analysis using principal component analysis and confirmed by confirmatory factor analysis using the robust maximum likelihood method and known group comparison. The correlation between compatible domain scores of MacNew and the World Health Organization's quality of life -brief questionnaire was used to assess concurrent validity.

Results: The original 3-factor model (Physical, Emotional and Social) of the MacNew with cross-loadings was confirmed: principal component analysis with $53.42 \%$ of the explained variance and confirmatory factor analysis with adequate fit for each of the three model fit criteria considered [root mean square error of approximation $=0.044(90 \% \mathrm{Cl}=0.031$ to 0.056); comparative fit index $=0.99 ; x^{2} / d f=1.39$ ]. Internal consistency of the MacNew was acceptable with Cronbach's a of 0.92 on the Global scale and on the domain scales ranging from $0.85-0.91$. Test-retest reliability was also found to be satisfactory with intraclass correlation coefficients of $>0.9$ for total and domain scores. A satisfactory level of concurrent validity was demonstrated with statistically significant correlations between compatible domain scores of MacNew and the World Health Organization's quality of life questionnaire (Pearson correlation ranging from 0.36-0.79).
\end{abstract}

Conclusions: The interviewer-administered Sinhalese MacNew is a valid and reliable patient-reported outcome measure to assess disease specific health-related quality of life among Sinhalese patients with stable angina.

Keywords: Factor analysis, Health-related quality of life, MacNew, Stable angina, Validation

\footnotetext{
* Correspondence: maheekas@yahoo.com

${ }^{1}$ Nutrition Coordination Division, 555/5 Elvitigala Mawatha, Colombo 5, Sri

Lanka

Full list of author information is available at the end of the article
} 


\section{Background}

Clinicians and policy makers increasingly recognize the importance of measuring health-related quality of life (HRQL) to inform patient management and policy decisions and it has become an important outcome measure in the evaluation of health interventions in chronic diseases including cardiology [1,2]. Two basic approaches to HRQL measurement are available: generic instruments that are applicable across a wide range of populations and specific instruments that focus on problems associated with single disease states, patient groups, or areas of function $[3,4]$.

The MacNew HRQL questionnaire (MacNew) is one of the more widely used coronary artery disease (CAD) -specific HRQL questionnaires [5]. The MacNew is a self-administered modification [6] of the original interviewer-administered Quality of Life after Myocardial Infarction questionnaire [7] and has since been translated into over 40 languages and psychometrically validated in 22 languages in patients with myocardial infarction, angina and ischaemic heart failure [8]. The MacNew consists of 27 questions with a Global HRQL score and HRQL scores in three domains, emotional, physical, and social, using a 7-point Likert scale with higher scores indicating better HRQL [6]. Construct validity of the 3-factor structure of the MacNew has been substantially confirmed in studies using factor analysis and structural equation modelling [8-12].

Although tools to assess disease-specific HRQL among patients with CAD have been developed, validated and extensively utilized internationally [5, 13], Sri Lanka lacks a validated language-specific tool to assess diseasespecific HRQL among patients with CAD. The present study was carried out to assess the construct validity of the interviewer-administered Sinhalese version of the MacNew HRQL instrument among patients being managed for stable CAD.

\section{Methods}

\section{Participants and procedure}

This validation study was conducted in the outpatient clinics of the premier public sector cardiology unit in Sri Lanka that were visited by the principal investigator daily to identify potential study participants. Patients with clinically diagnosed stable angina who were being or had been managed surgically (patients 4-8 weeks prior to and 12-16 weeks following coronary revascularization) or who were being managed medically were recruited for the study. Stable angina was defined as chest pain or discomfort that typically occurs with same amount of activity or emotional stress and is improved or relieved by rest and/or nitroglycerin [14]. The diagnosis of angina was made on the basis of angina symptoms and a positive stress test. The exclusion criteria included critically ill patients, patients with communication barriers (e.g., hearing/speech problems or those who cannot communicate in Sinhala) and patients with any other major illness/condition such as malignancy, residual effects of a cerebrovascular accident, limb amputation, severe obstructive airway disease, psychotic illnesses, alcoholic liver disease which can also affect HRQL.

Sampling was done using quota sampling method with special attention to ensure sufficient variability in clinical and socio-demographic characteristics. The sample size was based on recommendations by Tabachnick and Fidell [15] for confirmatory factor analysis (CFA) where 200 is considered adequate for small to medium sized models and we included equal proportions of patients from the following categories: medically managed, precoronary revascularization, and post-coronary revascularization. Consecutive recruitment was carried until the required sample size from each group was reached. The stability of the questionnaire was assessed by test-retest reliability where MacNew was re-administered to a subsample of 20 medically managed patients two weeks after baseline. The Ethical Review Committee of the Faculty of Medical Sciences at the University of Sri Jayawardhenepura, Sri Lanka approved the study and informed written consent was obtained prior to data collection. Trained interviewers administered the data collection instruments once informed written consent was obtained.

\section{Measurements}

Three interviewer administered questionnaires (IAQ) were used for data collection during this study;

IAQ- I: Questionnaire on Basic socio-demographic and clinical characteristics

IAQ- II: MacNew HRQL questionnaire (MacNew)

IAQ- III: World Health Organization's quality of

life-brief questionnaire (WHOQOL-BREF)

The variables included under IAQ- I were age, sex, main treatment modality, type of revascularization (PTCA/CABG), surgical status (pre-op/post-op) and grading of angina. Angina grading was done according to the Canadian cardiovascular society grading (CCS grading).

The Sinhalese translation of the MacNew was carried out according to standard forward- and backwardtranslation process [16, 17]. Two independent bilingual translators (one health professional, one lay person) performed the forward translation. Two different independent bilingual translators (one health professional, one lay person) translated back to English. The back-translated versions were compared with the original English version by the original authors of the MacNew to verify 
whether the original meaning of the items had been retained. This iterative process was continued until consensus was achieved for each item and answering option with adequate semantic comparability of the translated Sinhalese version to the original English MacNew. The study instrument was then pre-tested and used as an interviewer-administered questionnaire. The original 27item MacNew yields three domain scores and a Global score and scoring was done according to guidelines of the MacNew collaboration [6].

The validated Sinhalese version of WHOQOL-BREF was used to assess concurrent validity of the Sinhalese MacNew.

\section{Data Analysis}

1. Clinical and socio-demographic characteristics of the participants are described as categorical variables.

2. Construct validity was assessed by factor analysis (FA) and known group comparison. Suitability of data for FA was assessed [18] and found to be satisfactory. Factor analysis was conducted in two steps: exploratory factor analysis (EFA) by using principle component analysis (PCA) with oblimin rotation to identify the underlying factor structure and confirmatory factor analysis (CFA) to confirm the identified factor structure. Confirmatory factor analysis was performed using LISREL 8.8 using the robust maximum likelihood (RML) considering the non-normality of data distribution [19]. The present study used $x^{2} / \mathrm{df}$, root mean square error of approximation (RMSEA) and comparative fit index (CFI) to evaluate model fit. A model is considered good if following criteria are met: $x^{2} / \mathrm{df}<2$ [15], RMSEA $<0.05$ and CFI $>0.95$ [20]. Using known groups comparison, the median Global MacNew scores of a subsample of patients with a) less severe angina (CCS grade $<$ II) versus more severe angina (CCS grade $\geq \mathrm{II}$ ) and $\mathrm{b}$ ) pre- versus postrevascularization were compared using Mann-Whitney U test.

3. Concurrent validity was assessed by calculating Pearson correlation ( $r$ ) between compatible domain scores of MacNew and WHOQOL-BREF. Results were interpreted as follows: small $r=0.10-0.29$, medium $r=0.30-0.49$ or large $r=0.50-1.0$ [18].

4. Reliability was assessed for the Global and each domain using Cronbach's $\alpha$ for internal consistency and intraclass correlation coefficient (ICC) for test-retest reliability. Cronbach's $\alpha>0.70$ and ICC $>0.9$ were considered as satisfactory [21].

SPSS version 19.0 was used in the data analysis and the level of statistical significance was considered as $p<0.05$.

\section{Results}

\section{Patients}

The study sample consisted of 200 patients with stable angina; selected socio-demographic and clinical characteristics are given in Table 1 . There were more surgically managed $(67.0 \%)$ than medically managed patients (33.0\%); angina was present in $56.0 \%$ of the patients with the majority in CCS Grade I and II (76.0 \%). Using quota sampling equal proportions of males $(50 \%, n=$ $100)$ and females $(50 \%, n=100)$ were recruited ensuring an adequate representation of females. The mean age of the study participants was 57.7 years (SD, 8.7) with a range from 38 to 75 years.

\section{MacNew HRQL scores}

All patients completed the questionnaire with no missing items. The mean Sinhalese Global MacNew score was $5.0(\mathrm{SD}, 0.93)$ with a mean of $5.2(\mathrm{SD}, 1.04)$ on the

Table 1 Selected socio-demographic and clinical characteristics of the 200 patients with stable angina

\begin{tabular}{|c|c|c|}
\hline Characteristic & Frequency & $\%$ \\
\hline \multicolumn{3}{|l|}{ Sex } \\
\hline Male & 100 & $50 \%$ \\
\hline Female & 100 & $50 \%$ \\
\hline \multicolumn{3}{|l|}{ Age (years) } \\
\hline$\leq 40$ & 8 & 4.0 \\
\hline $41-50$ & 31 & 15.5 \\
\hline $51-60$ & 83 & 41.5 \\
\hline$>60$ & 78 & 39.0 \\
\hline \multicolumn{3}{|c|}{ Treatment Option $(n=200)$} \\
\hline Medical & 66 & 33.0 \\
\hline Surgical & 134 & 67.0 \\
\hline \multicolumn{3}{|c|}{ Type of Revascularization $(n=134)$} \\
\hline CABG & 65 & 48.5 \\
\hline PTCA & 69 & 51.5 \\
\hline \multicolumn{3}{|c|}{ Surgical Status $(n=134)$} \\
\hline Pre-operative & 67 & 50.0 \\
\hline Post-operative & 67 & 50.0 \\
\hline \multicolumn{3}{|c|}{ Anginal Status $(n=200)^{a}$} \\
\hline Angina present & 112 & 56.0 \\
\hline No Angina & 88 & 44.0 \\
\hline \multicolumn{3}{|c|}{ CCS Grading of Angina $(n=112)$} \\
\hline Grade I & 50 & 44.7 \\
\hline Grade II & 35 & 31.3 \\
\hline Grade III & 20 & 17.9 \\
\hline Grade IV & 7 & 6.1 \\
\hline
\end{tabular}

CABG Coronary Artery Bypass Graft, PTCA Percutaneous Transluminal Coronary Angioplasty, CCS Canadian Cardiovascular Society

aPresence of angina symptoms during previous 2 weeks 
Emotional domain, 4.9 (SD, 1.02) on the Physical domain, and 4.8 (SD, 1.00) on the Social domain. The Global and each domain score showed a negatively skewed distribution (Table 2).

\section{Construct Validity}

\section{Exploratory Factor Analysis}

Using PCA, the unrotated solution with six components exceeding an eigen value of 1 explained $65.2 \%$ of total variation. Direct oblimin rotation was used on the results of the 6-factor solution considering the medium size correlation (0.4) between Component 1 and 3. A decision was taken to retain the first three components or domains as the majority of the items loaded strongly $(>0.4)$, explaining $51.0 \%$ of the total variance which was consistent with the original factor structure of the Sinhalese MacNew. The pattern matrix revealed two items, \#17 (Sports/exercise limited) and \#27 (Sexual activities), with low communality values $(<0.3)$ which did not load on any of the components indicating their lack of alignment with the 3-factor model. Item \#27 was eliminated for socio-cultural reasons but item \#17 was retained to facilitate international comparisons.

Using oblimin rotation, PCA of the 26 items with the three forced factors increased the total variance explained from 50.9 to $53.4 \%$ with a more interpretable factor structure (Table 3 ) as follows:

All Emotional domain items loaded at $>0.4$ on Component 1 and was confirmed as the Emotional domain with items \#12 (Social activities) and \#23 (Burden on others) having cross-loadings similar to the original validation study [22]. Component 2 with items \#9 (Shortness of breath), \#14 (Chest pain), \#16 (Aching legs), \#17 (Sports/exercise limited) and \#19 (Dizzy or light-headed) which concentrate on physical symptoms were confirmed as the Physical domain. Social interaction items, \#12 (Social activities), \#13 (Others have less confidence in you), \#22 (Overprotective family), \#24 (Excluded), \#25 (Unable to socialize) and \#26 (Physically restricted) loaded on Component 3 which was confirmed as the Social domain.
Table 3 Pattern and Structure matrices of the three-factor solution of the 26-item Sinhalese MacNew

\begin{tabular}{|c|c|c|c|c|c|c|}
\hline \multirow[t]{3}{*}{ Item } & \multicolumn{3}{|c|}{ Pattern Matrix } & \multicolumn{3}{|c|}{ Structure Matrix } \\
\hline & \multicolumn{3}{|c|}{ Component } & \multicolumn{3}{|c|}{ Component } \\
\hline & 1 & 2 & 3 & 1 & 2 & 3 \\
\hline MAC4 & .899 & -.205 & .036 & .811 & .208 & .118 \\
\hline MAC7 & .845 & -.118 & .061 & .800 & .276 & .152 \\
\hline MAC1 & .806 & -.091 & -.112 & .750 & .253 & -.021 \\
\hline MAC2 & .748 & .098 & -.025 & .789 & .432 & .092 \\
\hline MAC8 & .743 & -.004 & .042 & .746 & .339 & .140 \\
\hline MAC5 & .727 & -.206 & .203 & .770 & .577 & .092 \\
\hline MAC15 & .643 & .295 & -.048 & .661 & .160 & .261 \\
\hline MAC3 & .608 & .101 & -.070 & .645 & .364 & .030 \\
\hline MAC20 & .546 & .181 & .159 & 649 & .458 & .265 \\
\hline MAC10 & .492 & .426 & -.342 & 639 & .585 & -.199 \\
\hline MAC21 & .473 & .152 & .114 & .557 & .387 & .204 \\
\hline MAC13 & .453 & .258 & -.423 & .514 & .385 & -.315 \\
\hline MAC18 & .448 & .356 & .110 & .624 & .579 & .236 \\
\hline MAC6 & .433 & .360 & .018 & .598 & .559 & .142 \\
\hline MAC9 & .003 & .772 & -.006 & .352 & .772 & .137 \\
\hline MAC19 & -.176 & .722 & .103 & .165 & .661 & .212 \\
\hline MAC16 & -.054 & .683 & -.012 & .253 & .656 & .106 \\
\hline MAC14 & .052 & .639 & .269 & .378 & .712 & .394 \\
\hline MAC11 & .329 & .480 & -.015 & .545 & .626 & .117 \\
\hline MAC23 & .398 & .468 & -.106 & .596 & .629 & .034 \\
\hline MAC 17 & .275 & .451 & .015 & .394 & .520 & -.318 \\
\hline MAC22 & -.067 & .018 & .758 & .042 & .128 & .753 \\
\hline MAC24 & .189 & .113 & .517 & .309 & .294 & .563 \\
\hline MAC12 & .233 & .342 & .467 & .451 & .534 & .562 \\
\hline MAC25 & .308 & .304 & .445 & .504 & .525 & .542 \\
\hline MAC26 & .234 & .425 & .439 & .484 & .511 & .549 \\
\hline
\end{tabular}

Extraction Method: Principal Component Analysis

Rotation Method: Oblimin with Kaiser Normalization

Major loadings for each item are given in bold

Underlined numbers in the Pattern Matrix indicate the domains to which each item was included in the original factor analysis study of MacNew [22]

Table 2 Descriptive statistics [mean and standard deviation (SD), interquartile range (IQR)] of the 27 item Sinhalese MacNew scores

\begin{tabular}{lllll}
\hline Statistics & \multicolumn{1}{l}{ MacNew scores } & & & \\
\cline { 2 - 5 } & Global & Emotional & Physical & Social \\
\hline Mean (SD) & $4.96(0.93)$ & $5.15(1.04)$ & $4.86(1.02)$ & $4.84(1.00)$ \\
Median & 5.07 & 5.36 & 5.00 & 4.92 \\
(IQR) & $(4.33-5.74)$ & $(4.36-5.93)$ & $(4.08-5.60)$ & $(4.17-5.62)$ \\
Skewness (SD) & $-0.46(0.17)$ & $-0.52(0.17)$ & $-0.39(0.17)$ & $-0.38(0.17)$ \\
Kurtosis (SD) & $-0.41(0.34)$ & $-0.51(0.34)$ & $-0.32(0.34)$ & $-0.49(0.34)$ \\
Minimum | Maximum & $2.30 \mid 6.89$ & $2.21 \mid 6.79$ & $1.70 \mid 7.00$ & $2.15 \mid 7.00$ \\
\hline
\end{tabular}


Analysis of the Structure matrix revealed good discrimination between the components (Table 3), i.e., the lowest factor loading of an item within its own domain is higher than the highest factor loading of a crossloading item from a different domain. This was true for all the Emotional, Physical, and Social domain items.

Following PCA, the MacNew consisted of a 3-domain structure with 26 items and items were allocated to the domain with the highest loading (Table 4). Based on the above structure, two models were identified for CFA.

\section{Confirmatory factor analysis}

The two models of the Sinhalese MacNew identified for CFA are detailed below.

Table 4 Item allocation to each domain of the 26 item Sinhalese MacNew

\begin{tabular}{|c|c|c|c|}
\hline \multirow[t]{2}{*}{ Item } & \multicolumn{3}{|l|}{ Domain } \\
\hline & Emotional & Physical & Social \\
\hline MAC1 - Frustrated & $\times$ & & \\
\hline MAC2 - Worthless & $\times$ & & \\
\hline MAC3 - Confident & $\times$ & & \\
\hline MAC4 - Down in the dump & $\times$ & & \\
\hline MAC5 - Relaxed & $\times$ & & \\
\hline MAC6 - Worn out & $\times$ & & \\
\hline MAC7 - Happy with personal life & $\times$ & & \\
\hline MAC8 - Restless & $x$ & & \\
\hline MAC9 - Shortness of breath & & $\times$ & \\
\hline MAC10 - Tearful & $x$ & & \\
\hline MAC11 - More dependent & & $\underline{x}$ & \\
\hline MAC12 - Social activities & & & $\times$ \\
\hline MAC13 - Others less confidence in you & $x$ & & \\
\hline MAC14 - Chest pain & & $\times$ & \\
\hline MAC15 - Lack self confidence & $\times$ & & \\
\hline MAC16 - Aching legs & & $\times$ & \\
\hline MAC17 - Sports/exercise limited & & $\times$ & \\
\hline MAC18 - Frightened & $\times$ & & \\
\hline MAC19 - Dizzy or light-headed & & $\times$ & \\
\hline MAC20 - Restricted or limited & $\underline{x}$ & & \\
\hline MAC21 - Unsure about exercise & $\underline{x}$ & & \\
\hline MAC22 - Overprotective family & & & $\times$ \\
\hline MAC23 - Burden on others & & $\underline{x}$ & \\
\hline MAC24 - Excluded & & & $\times$ \\
\hline MAC25 - Unable to socialize & & & $\times$ \\
\hline MAC26 - Physically restricted & & & $\times$ \\
\hline Total & 14 & 7 & 5 \\
\hline
\end{tabular}

$\times$ represent items compatible with the original factor structure $\underline{x}$ represent items showing discrepancies with the original factor structure
Model 1 The first model for CFA of the MacNew, Model 1, consisted of the 26 items with the following item allocations for the three domains without crossloadings.

\begin{tabular}{ll}
\hline Emotional domain: & Items \# 1, 2, 3, 4, 5, 6, 7, 8, 10, 13, 15, 18, 20, 21 \\
Physical domain: & Items \# 9, 11, 14, 16, 17, 19, 23 \\
Social domain: & Items \# 12, 22, 24, 25, 26 \\
\hline
\end{tabular}

Model 2 A second model for CFA of the MacNew, Model 2, also consisted of the 26 items and was developed taking into consideration the cross-loadings allowed in the original validation of the MacNew [22]. Cross-loading $(>0.4)$ similar to those in the original validation study was seen in three items (items \# 10, 13 and 26) in the present validation study (Pattern matrix in Table 3). These three items (given in bold) were allocated to more than one domain resulting in the following item allocation:

\begin{tabular}{ll}
\hline Emotional domain: & Items \# 1, 2, 3, 4, 5, 6, 7, 8, 10, 13, 15, 18, 20, 21 \\
Physical domain: & Items \# 9, 10, 11, 14, 16, 17, 19, 23, 26 \\
Social domain: & Items \# 12, 13, 22, 24, 25, 26 \\
\hline
\end{tabular}

The best fitting model was selected by performing CFA using RML estimation as recommended in LISREL 8.8 guidelines [19] for non-normal data.

Model fit statistics Model fit was evaluated based on $\chi^{2} / \mathrm{df}<2$, RMSEA $<0.05$ and CFI $>0.95$. Neither of the models showed an adequate fit. In Model 1, the CFI showed a fit value above the standard 0.95 . However, the other indicators were below the acceptable range of model fit. Therefore, it was decided to modify both models by adding error co-variances and cross-loadings, taking into consideration the conceptual validity of the model fit improvement suggestions made by LISREL.

Model fit statistics after modifications The best fitting model (modified Model 1) consisted of following item allocation (cross-loaded items are given in bold):

\begin{tabular}{ll}
\hline Emotional domain with 15 items: & $\begin{array}{l}1, \mathbf{2}, 3,4,5, \mathbf{6}, 7,8,10,13,15,18,20, \\
21 \text { and } \mathbf{2 3}\end{array}$ \\
Physical domain with 9 items: & $\mathbf{6}, 9,11,14,16,17,19, \mathbf{2 3}$ and $\mathbf{2 6}$ \\
Social domain with 6 items: & $\mathbf{2}, 12,22,24,25$ and $\mathbf{2 6}$
\end{tabular}

Modified Model 1, with the four cross-loading items, showed the best fit (Table 5). In this model, all three 
Table 5 Summary of model fit statistics for the 3-factor model of Sinhalese MacNew after modifications

\begin{tabular}{lllllc}
\hline Model & \multicolumn{2}{l}{ Fit indices } & & \\
\cline { 2 - 6 } & $X^{2}$ & $\mathrm{df}$ & $\mathrm{p}$ & CFI & RMSEA \\
\hline Model 1 & 289.80 & 209 & 0.00018 & 0.99 & 0.044 \\
Model 2 & 319.83 & 210 & $<0.00001$ & 0.99 & 0.051
\end{tabular}

$x^{2}$ Satorra-Bentler scaled Chi-square test, CFI Comparative fit index ( $>0.9$ desired), RMSEA Root mean square error of approximation ( $<0.05$ desired)

model fit criteria considered in the study showed adequate fit $\left[X^{2} / \mathrm{df}=1.39\left(\chi^{2}=289.8 ; \mathrm{df}=209\right) ;\right.$ RMSEA $=0.044(90 \% \mathrm{CI}=0.031$ to 0.056$) ; \mathrm{CFI}=0.99)]$. Modified Model 1 was significantly different from Model 2 $\left(p<.001, \mathrm{x}^{2 \mathrm{di}} \mathrm{ff}=30.03, \mathrm{dfdi} f \mathrm{ff}=1\right)$.

The factor loadings in CFA indicate how strongly each item is predicted by the underlying latent factors and the standardized parameter estimates of the final modified 3 -factor model of the 26-item MacNew are shown in Fig. 1. All the factor loadings of this model are statistically significant at $p<0.05$.

\section{Known group comparison}

As an additional approach to establishing construct validity, we compared median Sinhalese MacNew HRQL scores in the sub-groups of patients with selected clinical characteristics, CCS grade and revascularization as an additional method of assessing construct validity using the Mann-Whitney U test (Table 6). Patients with CCS grade I had a significantly lower HRQL $(\mathrm{Md}=5.35, n=$ 138) than patients with a CCS grade $\geq$ II $(\mathrm{Md}=5.17, n=$ 62). Post-revascularization HRQL was significantly higher $(\mathrm{Md}=5.11, n=67)$ than pre-vascularization HRQL $(\mathrm{Md}=$ $4.78, n=67)$.

\section{Concurrent Validity}

Pearson correlations ( $r$ ) between compatible domain scores of Sinhalese MacNew and WHOQOL-BREF were statistically significant with highest correlation observed in the Emotional domain $(r=0.79)$ followed by Physical $(r=0.73)$ and Social $(r=0.36)$ domains.

\section{Reliability of The MacNew Internal consistency}

Internal consistency of the Sinhalese MacNew was assessed separately for the Global and each domain scales with Cronbach's $\alpha$ of 0.92 for the Global scale and 0.91 for the Emotional, 0.85 for the Physical and 0.86 for the Social domains (Table 7).

\section{Test-retest reliability}

Test-retest reliability of the MacNew was also found be satisfactory with global and all three domain scores having high correlations (ICC > 0.99) (Table 7).

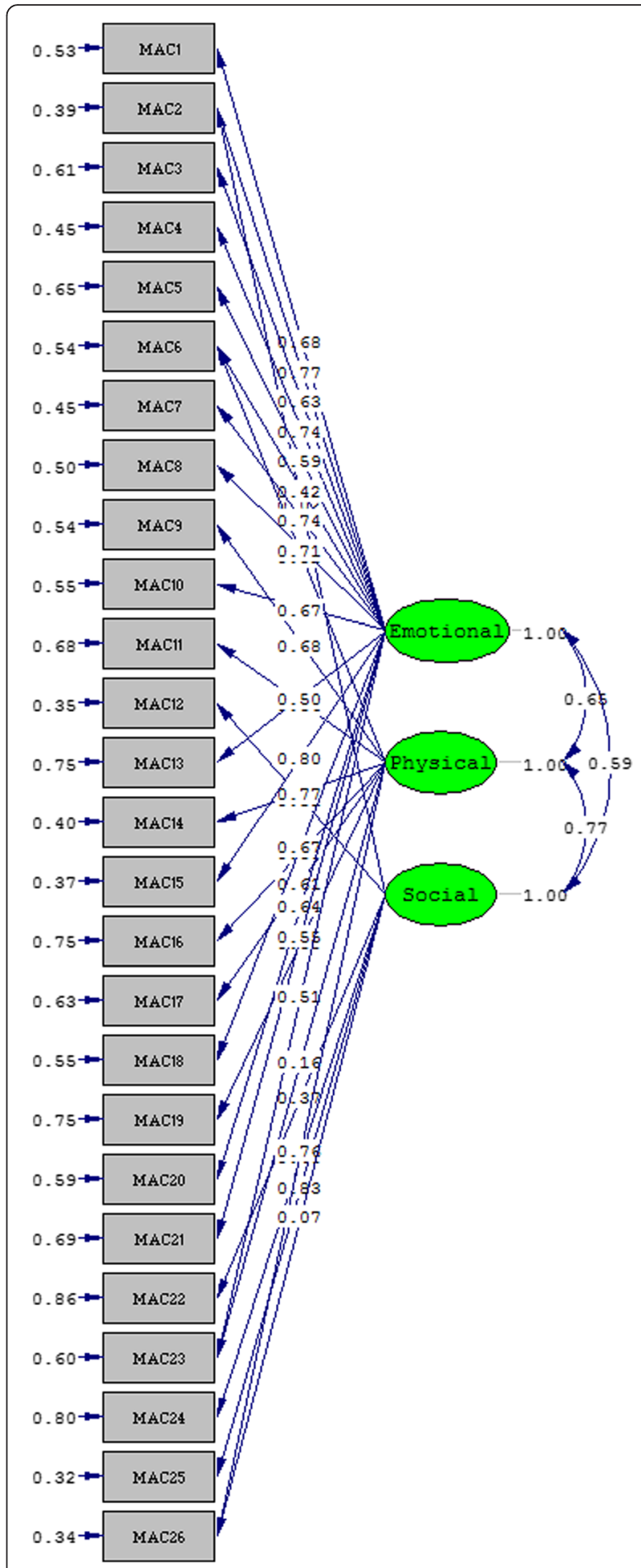

Fig. 1 Path diagram of the best fitting model - modified 3- factor 26- item Sinhalese MacNew (Chi-square $=289.80, P$-value $=0.00018$, RMSEA - 0.044) 
Table 6 Comparison of median scores for Global Sinhalese MacNew scores according to angina severity and revascularization status

\begin{tabular}{|c|c|c|c|}
\hline Clinical category & No: & Median (IQR) & Significance $^{\mathrm{a}}$ \\
\hline \multicolumn{4}{|l|}{ Angina severity $(n=200)$} \\
\hline $\mathrm{CCS}^{\mathrm{b}}$ grade $<\|$ & 138 & $5.35(4.43-5.84)$ & \multirow{2}{*}{$\begin{array}{l}U=1556.5 \\
Z=-2.092 \\
p=0.036\end{array}$} \\
\hline CCS grade $\geq \|$ & 62 & $5.17(4.34-5.69)$ & \\
\hline \multicolumn{4}{|c|}{ Revascularization status $(n=134)$} \\
\hline Pre-revascularization & 67 & $4.78(4.11-5.18)$ & \multirow{2}{*}{$\begin{array}{l}U=1646.5 \\
Z=2.78 \\
p=0.005\end{array}$} \\
\hline Post-revascularization & 67 & $5.11(4.44-5.62)$ & \\
\hline
\end{tabular}

$I Q R$ interquartile range

${ }^{a}$ Mann-Whitney U test

${ }^{\mathrm{b}}$ Canadian Cardiovascular Society grading of angina

\section{Discussion}

Sri Lanka lacks a language specific validated tool to assess disease-specific HRQL among Sinhalese patients with CAD. The MacNew HRQL questionnaire was therefore translated into Sinhalese and was tested for reliability and validity in 200 patients with stable angina. The original 3-factor model (Physical, Emotional and Social) of the self-administered MacNew with crossloadings was confirmed with the interviewer-administered Sinhalese MacNew with adequate fit for each of the three model fit criteria considered [RMSEA $=0.044(90 \%$ $\mathrm{CI}=0.031$ to 0.056$\left.) ; \mathrm{CFI}=0.99 ; \mathrm{X}^{2} / \mathrm{df}=1.39\right]$. Internal consistency of the Sinhalese MacNew was acceptable with Cronbach's $\alpha$ of 0.92 on the Global score and domain scores ranging from $0.85-0.91$. Test-retest reliability was also found to be satisfactory with an ICC of $>0.9$ for the total and each domain. The intervieweradministered Sinhalese MacNew is a reliable and valid patient-reported outcome measure that can be recommended for assessing disease specific HRQL among Sinhalese patients with stable CAD.

Table 7 Internal consistency and test-retest reliability of the overall instrument and the three domains of the Sinhalese MacNew

\begin{tabular}{lll}
\hline Internal Consistency & No. of items & Cronbach's a \\
Global & 26 & 0.92 \\
Emotional & 14 & 0.91 \\
Physical & 13 & 0.85 \\
Social & 13 & 0.86 \\
& & \\
Test-retest reliability & ICC $^{\mathrm{a}}$ & \\
Global & 0.99 & \\
Emotional & 0.99 & \\
Physical & 0.99 & \\
Social & 0.99 & \\
\hline
\end{tabular}

${ }^{\mathrm{a}}$ Intraclass Correlation Coefficient
However, since most items loaded strongly onto the first three of six components with EFA using PCA as the extraction method, a forced 3-factor, direct oblimin rotation was applied to the results of the 6-factor solution. As the original MacNew analyses used varimax rotation $[6,22]$, this may explain the observations in the present study where direct oblimin rotation was used. With PCA, the majority of items in the present forced 3factor model loaded strongly on only one component, or domain, making the identification of three components straightforward. Since all items, except for item 27 (Sexual activities) which was deleted for cultural reasons, loaded on factors in a similar way to the original scoring [22], but with less cross-loading, the three components, Emotional, Physical and Social, were consistent with the original 3-domain MacNew, resulting in the 26-item Sinhalese version of the MacNew.

Two items in the MacNew failed to load $>0.4$ on any of the components (item \#17, Sports/exercise limited and item \#27, Sexual activities) and both had low communalities. This may be explained by the socio-cultural context of the study population. During administration of the questionnaire, it was evident that respondents gave an answer to item \#17 which they considered as suitable even though their disease did not affect their sports/exercise activities as these activities were not considered as part of their daily routine. Although it was felt that this item failed to tap the impact of CAD on HRQL in the Sri Lankan cultural context, a decision was taken to retain item \#17 to facilitate international comparisons. With regards to item \#27 on "Sexual activities", it was apparent that respondents were reluctant to genuinely answer the question and that social desirability bias may have played a role in the answers given by the Sri Lankan patients. Since this item had also been omitted from the original and Farsi validation studies [22, 23], a decision was taken to proceed with analysis without item \#27 for cultural reasons. However, this problem might not have arisen if the MacNew had been self-administered as originally intended. In other language validation studies MacNew was used as a "self-administered" questionnaire. With the lack of reading comprehension in a large number of the study participants and in the nation, the current study used MacNew as an "interviewer-administered" questionnaire. The effects of questionnaire administration mode on final outcome of HRQL studies is inconclusive: some studies have documented evidence for higher mean values in the interviewer-administered mode compared to selfadministered while others have concluded that the mode of administration has no effect on the final outcome [24].

The decision to include all items with a factor weight of $>0.40$ in the original factor analysis [22] lead to crossloading of items. Of the 26 items, all but four (items $\# 11, \# 20$, \#21 and \#23) loaded consistently with the item 
allocation of the original domain scoring system of the MacNew [22]. Content analysis revealed that the Physical domain on to which items \#11 (More dependent) and \#23 (Burden on others) had loaded could be justified considering the fact of being more dependent due to impaired physical fitness and therefore feeling like a burden on others. However, items \#20 (Restricted or limited) and \#21 (Unsure about exercise) loading on the Emotional domain rather than on the Physical domain could not be readily explained through the concepts of HRQL. Item \#20 cross-loaded at 0.458 onto the Physical domain as in the original factor structure [6]. This may well be due to the ambiguous wording of this item: "In general, during the last 2 weeks how much have you been restricted or limited as a result of your heart problem?" Only item \#21 loaded on to the Emotional component without cross-loading on to either the Physical or Social domains to which it was originally assigned. The Sinhalese version of the MacNew obviously taps more into the emotional concept of this item, addressing more the feeling of being insecure, than the actual performance of physical exercise. However, a decision was taken to retain item \#21 to facilitate international comparisons.

Since some researchers have questioned the validity of including all items with a factor weight of $>0.40[25,26]$, item allocation for the Sinhalese MacNew was initially done according to the highest factor weight resulting in a structure without cross-loadings (Model 1). This model (Model 1) explained $53.42 \%$ of the total variance and was then subjected to CFA using MRL estimation compared with another 26-item 3-factor model (Model 2) similar to it except for allowing three cross-loadings. Model 1, with the addition of four cross-loadings as suggested by LISREL demonstrated the best fit of these data. Since the $X^{2}$ value can be affected by a large sample size, its validity in assessing model fit has been questioned [19] and the ratio between the $X^{2}$ value and the degrees of freedom (df) has been recommended as a better indicator of model fit than the $x^{2}$ value alone [15]. The $\chi^{2} / \mathrm{df}$ ratio should be $<2$ in order to claim adequate fit and, in Model 1, the ratio was 1.39 indicating adequate fit. Although contrasting findings have been reported, for example in the English MacNew [25] and the German MacNew [27], the CFA in the current study suggested a 3-factor model for the MacNew. The interviewer-administered Sinhalese 3-factor MacNew is consistent with the original 3-factor structure of the selfadministered MacNew [6] that has been substantially confirmed in each of the independently generated study reports in languages as diverse as Norwegian [11], Dutch [10], Chinese [28], Spanish [9] and Hungarian [29].

Comparison of the median MacNew scores on selected clinical characteristics was performed as an additional method of assessing construct validity. As expected, higher Global HRQL scores were observed in patients with less severe angina (CCS grade I) as opposed to more severe angina (CCS grade $\geq$ II) and patients in the post-operative period as opposed to pre-operative period. Comparison of MacNew HRQL scores in clinically different groups has yielded results similar to those observed in present study [6, 22, 30, 31].

Concurrent validity of the Sinhalese MacNew was also found to be satisfactory with statistically significant Pearson correlation values ranging from $0.36-0.79$. The value for the Social domain is lowest at $r=0.36$ which could be due to the fact that the social items of the WHOQOL-BREF do not match the content of the social items of the MacNew.

In international studies, the reliability of the selfadministered MacNew is high with Cronbach's $\alpha$ internal consistency values for the three domains reported to range from 0.82 to 0.97 and ICC values ranging from $0.73-0.95[6,8-11,23,25-28,30]$. In the present study, the Sinhalese interviewer-administered MacNew demonstrated similar results with both Cronbach's $\alpha$ of 0.92 for Global and 0.91, 0.85 and 0.86 for Emotional, Physical and Social domains respectively and an ICC of $>0.99$ indicating a satisfactory level of test-retest reliability.

The main limitation of this study is the fact that the Sinhalese MacNew was interviewer-administered and not self-administered. Although there are legitimate reasons for this as a large proportion of both the study and national populations lack reading comprehension, this raises the problem of comparing the present results with other published data where the MacNew was selfadministered. However, the reliability and validity results with interviewer administration are largely consistent with the results of the self-administered studies. A second limitation is the lack of results for formal content validity index indicating the content validity of the translated tool. However, this has been addressed by the iterative standard forward- and backward-translation process, which was carried out until all conceptual and cultural translational issues had been resolved with the aid of the translators and authors of the original version. The absence of MacNew responsiveness data is another limitation but, now that the reliability and validity of the Sinhalese MacNew has been established, this can be remedied by focusing on responsiveness as an outcome in future studies conducted in Sri Lanka.

\section{Conclusions}

The psychometric analyses of the Sinhalese MacNew demonstrate good construct validity and reliability in stable angina patients in Sri Lanka. The observations in the present study confirm the multidimensionality of the 26-item interviewer-administered MacNew with 3 domains comparable to the original English version and 
numerous other language versions. The psychometric analyses of the Sinhalese MacNew demonstrate good construct validity and reliability. The interviewer-administered disease-specific Sinhalese MacNew is a valid and reliable patient-reported outcome measure and can be recommended for assessing HRQL in stable angina patients in Sri Lanka.

\section{Competing interests}

$\mathrm{SH}$ and NBO are co-developers of the MacNew questionnaire while the remaining authors declare that they have no competing interests.

\section{Authors' contributions}

KLMDS conceived of the study and participated in its design, collected data, performed the statistical analysis and drafted the manuscript. DBDLS participated in the design of the study, helped in the statistical analysis and manuscript writing. PF participated in the design of the study, and participated in its design and supervised the study. GNLG participated in the study design and supervision. $\mathrm{SH}$ made substantial contributions to the analysis and interpretation of data and involved in revising the manuscript critically for important intellectual content. NBO made substantial contributions to the interpretation of data and was involved in revising the manuscript critically for important intellectual content. All authors read and approved the final manuscript. KLMDS, NBO and SH are accountable for all aspects of the work ensuring that questions related to the accuracy or integrity of any part of the work are appropriately investigated and resolved.

\section{Acknowledgements}

We would like to thank Dr. Ruwan Ekanayake, Senior Consultant Cardiologist at the National hospital of Sri Lanka for his valuable contributions at the design phase of the study and the staff of the cardiology unit for their co-operation. Most importantly, we acknowledge study participants for willingly participating in the study.

\section{Author details}

${ }^{1}$ Nutrition Coordination Division, 555/5 Elvitigala Mawatha, Colombo 5, Sri Lanka. ${ }^{2}$ Department of Community Medicine, University of Colombo, Colombo, Sri Lanka. ${ }^{3}$ Department of Community Medicine, University of Sri Jayawardhenepura, Nugegoda, Sri Lanka. ${ }^{4}$ Emergency Response to Artemisinin Resistance (ERAR) and other Vector Borne \& Parasitic Diseases, World Health Organization, Hà Nội, Viet Nam. ${ }^{5}$ Department of Medical Psychology, Innsbruck Medical University, Innsbruck, Austria. ${ }^{6}$ College of Health Sciences, University of Wisconsin-Milwaukee, Milwaukee, USA.

Received: 15 September 2015 Accepted: 9 March 2016

\section{Published online: 15 March 2016}

\section{References}

1. Rumsfeld JS, Alexander KP, Goff Jr DC, Graham MM, Ho PM, Masoudi FA, et al. Cardiovascular health: the importance of measuring patient-reported health status: a scientific statement from the American Heart Association. Circulation. 2013. doi:10.1161/CIR.0b013e3182949a2e.

2. Anker SD, Agewall S, Borggrefe M, Calvert M, Jaime Caro J, Cowie MR, et al. The importance of patient-reported outcomes: a call for their comprehensive integration in cardiovascular clinical trials. Eur Heart J. 2014. doi:10.1093/eurheartj/ehu205

3. Guyatt GH, Feeny DH, Patrick DL. Measuring Health-Related Quality of Life. Ann Intern Med. 1993;118:622-9.

4. Ware JE, Kosinski M, Keller SD. The SF-36: Physical and mental health summary scores: a user's manual. Boston (MA): The Health Institute; 1994.

5. McGee H. Health-Related Quality of Life in Cardiac Patients. In: Perk J, Gohlke H, Hellemans I, Sellier P, Mathes P, Monpère C, McGee H, Saner H, editors. Cardiovascular prevention and rehabilitation. London: Springer; 2007. p. $256-68$

6. Valenti L, Lim L, Heller RF, Knapp J. An improved questionnaire for assessing quality of life after myocardial infarction. Qual Life Res. 1996:5:151-61.

7. Oldridge N, Guyatt G, Jones N, Crowe J, Singer J, Feeny D, et al. Effects on quality of life with comprehensive rehabilitation after acute myocardial infarction. Am J Cardiol. 1991;67:1084-9.
8. MacNew.org 2015. Information [Internet]. 19 March 2015 [cited 29 May 2015] Available at: www.macnew.org

9. Brotons CC, Ribera SA, Permanyer MG, Cascant CP, Moral PI, Pinar SJ, et al. Adaptation of the MacNew QLMI quality of life questionnaire after myocardial infarction to be used in the Spanish population [in Spanish]. Medicina Clinica (Barcelona) [e-journal]. 2000;115:768-71. Abstract only. Available through: PubMed database [Accessed 12 February 2013].

10. de Gucht V, van Elderen T, van der Kamp L, Oldridge N. Quality of life after myocardial infarction: translation and validation of the MacNew Questionnaire for a Dutch population. Qual Life Res. 2004. doi:10.1023/B QURE.0000040792.25240.38.

11. Hiller A, Helvik AS, Kaasa S, Slørdahl SA. Psychometric properties of the Norwegian MacNew Heart Disease health-related quality of life inventory. Eur J Cardiovasc Nurs. 2010. doi:10.1016/j.ejcnurse.2010.01.002.

12. Höfer S, Saleem A, Stone J, Thomas R, Tulloch H, Oldridge N. The MacNew Heart Disease Health-Related Quality of Life Questionnaire in Patients with Angina and Patients with Ischaemic Heart Failure. Value Health. 2012. doi:10.1016/j.jval.2011.07.003.

13. Dempster M, Donnelly M. Measuring health-related quality of life among people with ischaemic heart disease. Heart. 2000. doi:10.1136/heart.83.6.641.

14. Swanton RH. Ch. 2.14. In: Ledingham JGG, Warrell DA, editors. Concise Oxford Textbook of Medicine. Oxford: Oxford University Press; 2000.

15. Tabachnick BG, Fidell LS. Using multivariate statistics. 5th ed. Boston: Pearson/Allyn \& Bacon; 2007.

16. Ware Jr JE. The status of health assessment 1994. Annu Rev Public Health. 1995;16:327-54

17. Medical Outcomes Trust Committee in 2002 [Scientific Advisory Committee of Medical Outcomes Trust]. Assessing health status and quality-of-life instruments: attributes and review criteria. Qual Life Res. 2002. doi:10.1023/ A:1015291021312.

18. Pallant J. SPSS survival manual: a step by step guide to data analysis using SPSS for Windows (version 15). 3rd ed. New South Wales: Allen and Unwin; 2007.

19. Joreskog KG, Sorbom D. LISREL 8: User's reference guide. Chicago: Scientific Software International Inc.; 1996.

20. Browne MW, Cudeck R. Alternate ways of assessing model fit. In: Bollen A Long JS, editors. Testing structural equation models. Newbury Park: Sage; 1993. p. 136-62.

21. Abramson JH, Abramson ZH. Survey Methods in Community Medicine. 5th ed. Edinburgh: Churchill-Livingston; 1999.

22. Lim LL-Y, Valenti LA, Knapp JC, Dobson AJ, Plotnikoff R, Higginbotham N, et al. A self-administered quality of life questionnaire after acute myocardial infarction. J Clin Epidemiol. 1993:46:1249-56.

23. Asadi-Lari M, Javadi H, Melville M, Oldridge N, Gray D. Adaptation and administration of the MacNew quality of life questionnaire after myocardial infarction in an Iranian population. Health Qual Life Outcomes. 2003. doi:10. 1186/1477-7525-1-23.

24. Bowling A. Mode of questionnaire administration can have serious effects on data quality. J Public Health. 2005. doi:10.1093/pubmed/fdi031.

25. Dempster M, Donnelly M, O'Loughlin C. The validity of the MacNew quality of life in heart disease questionnaire. Health Qual Life Outcomes. 2004. doi: 10.1186/1477-7525-2-6

26. Ribera A, Permanyer-Miralda G, Alonso J, Cascant P, Soriano N, Brotons C. Is psychometric scoring of the McNew Quality of Life after Myocardial Infarction questionnaire superior to the clinimetric scoring? A comparison of the two approaches. Qual Life Res. 2006. doi:10.1007/s11136-005-2291-3.

27. Gramm L, Farin E, Jaeckel WH. Psychometric properties of the German version of the MacNew heart disease health-related quality of life questionnaire. Health Qual Life Outcomes. 2012. doi:10.1186/1477-7525-10-83.

28. Yu DS, Thompson DR, Yu CM, Oldridge NB. Validation of the Chinese version of the MacNew heart disease health-related quality of life questionnaire. J Eval Clin Pract. 2008. doi:10.1111/j.1365-2753.2007.00863.x.

29. Bakai J, Höfer S, Oldridge N, Lukács M. MacNew Heart Disease Healthrelated Quality of Life kérdoív magyarországi validálása. Kardiovaskuláris prevenció és rehabilitáció. 2011:4:13-20.

30. Höfer S, Benzer W, Schüssler G, von Steinbüchel N, Oldridge NB. Healthrelated quality of life in patients with coronary artery disease treated for angina: validity and reliability of German translations of two specific questionnaires. Qual Life Res. 2003. doi:10.1023/A:1022272620947.

31. Dixon T, Lim LLY, Oldridge NB. The MacNew heart disease health-related quality of life instrument: Reference data for users. Qual Life Res. 2002. doi: 10.1023/A:1015005109731. 